\title{
Saussure e a historicidade da língua ${ }^{1}$
}

\section{Saussure und die Geschichtlichkeit der Sprache}

\author{
Hans Lösener* \\ loesener@ph-heidelberg.de \\ Pädagogische Hochschule Heidelberg \\ Aroldo Garcia dos Anjos** \\ aroldodosanjos@gmail.com \\ Universidade Federal de Pelotas
}

\begin{abstract}
RESUMO: O presente trabalho discute o lugar que a historicidade ocupa nas reflexões de Ferdinand de Saussure, tomando por base excertos tanto do Curso de Linguística Geral quanto dos Escritos de Linguística Geral. Primeiramente, objetiva mostrar até que ponto a concepção saussuriana da arbitrariedade, do sistema e do valor abre a possibilidade de uma historicização radical da língua. Para tanto, essa historicização é ilustrada pela comparação com um autor contemporâneo a Saussure e com outro atual, a saber, Hermann Paul e Steven Pinker. Com isso, busca-se mostrar que a reflexão saussuriana é ainda tão relevante na época da linguística cognitiva como foi nos tempos dos neogramáticos positivistas.
\end{abstract}

PALAVRAS-CHAVE: Historicidade. Valor. Saussure. Paul. Pinker.

ZUSAMMENFASSUNG: Anhand von Auszügen aus dem Cours de linguistique générale und den Écrits de linguistique générale diskutiert die vorliegende Arbeit den Stellenwert, den die Geschichtlichkeit in den Überlegungen von Ferdinand de Saussure einnimmt. Zu diesem Zweck wird gezeigt, inwieweit die Saussuresche Konzeption von Arbitrarität, System und Wert die Möglichkeit einer radikalen Geschichtlichkeit der Sprache eröffnet. Anschließend wird diese Geschichtlichkeit durch einen Vergleich mit einem Zeitgenossen Saussures und einem anderen aktuellen Autor veranschaulicht, nämlich Hermann Paul und Steven Pinker. Dabei wird gezeigt, dass die Saussuresche Reflexion in der Zeit der kognitiven Linguistik noch genauso relevant ist, wie sie es in der Zeit der positivistischen Neogrammatiker war.

SCHLÜSSELWÖRTER: Geschichtlichkeit. Wert. Saussure. Paul. Pinker.

\footnotetext{
${ }^{1}$ A permissão para traduzir o artigo do Prof. Dr. Hans Lösener para o português foi dada pelo autor, por e-mail, em 24 de julho de 2020. A permissão da editora Gunter Narr, responsável pela revista Kodikas/Code, foi concedida por Kathrin Heyng por e-mail, no dia 27 de janeiro de 2021. O artigo "Saussure und die Geschichtlichkeit der Sprache" foi originalmente publicado em alemão na revista Kodikas/Code, v. 23, p. 97-108, Tübingen: Ed. Gunter Narr, 2000. O texto encontra-se disponível na página: http://sprachtheorie.de/wp-content/uploads/2012/09/Lösener-Saussure1.pdf.

* Professor de língua e literatura alemã e de sua didática, coordenador do curso de Pedagogia Teatral. O autor publicou, entre outros: Gegenstimmen. Eine Dramendidaktik. (2017), Zwischen Wort und Wort. Interpretation und Textanalyse (2006), Der Rhythmus in der Rede. Linguistische und literaturwissenschaftliche Aspekte des Sprachrhythmus (1999).

** Doutorando em Letras pela UFPel. Integrante do grupo Linguística, literatura e arte, vinculado ao CNPq. Professor de alemão e tradutor.
} 
Pois a fama é, afinal, apenas a personificação de todos os malentendidos que se congregam ao redor de um nome novo.

$(\text { Rilke })^{2}$

As verdadeiras autoridades na ciência são raras. Não é suficiente deixar como herança uma grande obra de uma vida para ser contado entre os grandes de sua área. O que faz de um cientista uma verdadeira autoridade é o consenso entre as escolas e disciplinas que confirma permanentemente o significado da obra que marcou época. Mas este consenso tem, não raramente, algo de uma pirâmide egípcia: ele pode ser enorme em escala e desafiar inabalavelmente a passagem do tempo, mas concede glória eterna somente àquele que ele amuralhou para sempre dentro de si. No momento em que a autoridade se torna inatacável, ela deve cair em silêncio. Ela se torna uma múmia que é citada, mas não mais lida, pois, na ciência, somente o que está vivo é controverso; o incontroverso pertence definitivamente ao passado.

O linguista genovês Ferdinand de Saussure poderia ser uma dessas autoridades indiscutíveis. Sua fama se funda no tremendo impacto que o Cours de linguistique générale, publicado em 1916, teve na linguística europeia, mas também na sociologia, na etnologia e na psicologia. Claude Lévi-Strauss, Michel Foucault e Jacques Lacan se referiram ao Cours, assim como Roman Jakobson, Karl Bühler, Hans Glinz, Jost Trier e Louis Hjelmslev. Com isso parece estabelecer-se de uma vez por todas que papel compete a Saussure: ele é o pai do estruturalismo e, portanto, uma das grandes autoridades científicas do século $X X{ }^{3}$ A razão da fama de Saussure seria então, ao mesmo tempo, um motivo para não o ler hoje, ou no máximo, para lê-lo por um interesse histórico, pois os tempos frutíferos do estruturalismo terminaram, e, se o significado de Saussure se esgotar em seu papel de fundador do estruturalismo, seu trabalho merece apenas um lugar de honra na galeria dos outrora grandes da linguística.

Mas Saussure não corresponde à imagem que dele foi feita. Ele não pode ser reduzido ao episódio estruturalista da linguística, porque ele permaneceu presente, e seus conceitos não perderam nada de sua atualidade; não apenas o fluxo ininterrupto

\footnotetext{
${ }^{2}$ Rainer Maria Rilke, Rodin (1902, p. 351, tradução minha).

${ }^{3}$ É assim que ele continua sendo visto em muitos manuais linguísticos introdutórios, por exemplo por Gerd Lingrün (in: Arnold \& Sinemus, 1974, p. 150), Gerhard Nickel (1979, p. 66), Heidrun Pelz (1987, p. 27), Harro Gross (1988, p. 22) e Christa Dürscheid (1994, p. 23).
} 
de novas publicações sobre seu trabalho testemunha isso; torna-se sobretudo evidente quando se lê novamente os escritos de Saussure. Tradicionalmente, no entanto, isto tem sido difícil de ser alcançado na Alemanha. É verdade que o Cours foi traduzido para o alemão por Herman Lommel em 1931 (e, a propósito, somente em 1959 para o inglês), mas desde então não foi publicado nem um suplemento nem uma revisão, muito menos uma edição crítica da obra. Como o livro que estabeleceu a fama de Saussure não foi por ele mesmo redigido, mas foi publicado somente três anos após sua morte com base nas anotações de Charles Bally e Albert Sechehaye, pesa ainda mais a falta de uma edição crítica, como a providenciada para o francês por Tullio De Mauro em 1972. Lemos Saussure hoje - quando o lemos em alemão como se nunca tivesse existido a publicação por Rudolf Engler (1967) das fontes do Cours e dos manuscritos de Saussure, apesar de Ludwig Jäger já ter apontado em 1975 as distorções resultantes em nossa recepção de Saussure. Só agora essa situação começa a mudar fundamentalmente, graças a um livro intitulado Linguistik und Semiologie 4 , publicado por Johannes Fehr em 1997, no qual ele traduziu e comentou as notas manuscritas de Saussure. Esse volume talvez venha a ser um marco na recepção alemã de Saussure, pois poderia ajudar a viabilizar o acesso a outro Saussure, a um Saussure que não representa tanto uma autoridade reconhecida do passado, mas, antes pelo contrário, um desafio para a discussão teórica linguística aqui e agora.

De fato, esse Saussure diferencia-se fundamentalmente de seu famoso homônimo estruturalista, o que se torna imediatamente explícito quando se compara a imagem clássica de Saussure com o que pode ser lido no próprio Saussure. 0 Saussure estruturalista ainda é encontrado na maioria das introduções à linguística atualmente disponíveis no mercado livreiro, onde ele pode, contudo, desempenhar vários papéis e, volta e meia, até mesmo é tratado como um precursor de Chomsky ${ }^{5}$ ou um pólo oposto a Humboldt ${ }^{6}$, mas sempre marca o ponto de inflexão a partir do

\footnotetext{
${ }^{4}$ N. do T.: Linguistik und Semiologie (Linguística e Semiologia), de Johannes Fehr, ainda não possui tradução para o português. Doravante, são minhas todas as traduções das citações dessa obra, do original alemão para a língua portuguesa, referenciadas como: SAUSSURE/FEHR, 1997.

${ }^{5}$ Assim escreve John Lyons a respeito da dicotomia saussuriana de langue e parole: "Chomsky fez recentemente mais ou menos a mesma distinção com os conceitos de 'competência' e 'desempenho' linguístico" (LYONS, 1971, p. 52, tradução minha). Harro Gross também faz essa equiparação (1988, p. 22).

${ }^{6}$ Enquanto Saussure, escreve Brigitte Bartschat, considera a langue apenas como um "estoque de signos ligados entre si por relações paradigmáticas", para Humboldt ela também é "energeia, criação perpétua, não apenas ergon, o criado" (Bartschat, 1996, p. 67). Aqui a crítica da concepção de
} 
qual a dimensão histórica da língua foi excluída da linguística. A exclusão da historicidade, ou seja, a mudança incessante da língua no tempo, resulta assim do conceito de sistema de Saussure e da separação entre sincronia e diacronia, langue e parole, que ele supostamente propagou e que é responsável pela redução estruturalista da língua a uma mera estrutura linguística. ${ }^{7}$ A frase final do Cours, que comprovadamente não é do próprio Saussure, foi lida também nesse sentido:

la linguistique a pour unique et véritable objet la langue envisagée en elle-même et pour elle-même (SAUSSURE, 1972, p. 317) ${ }^{8}$.

Assim que nos damos ao trabalho de não ler mais apenas o Cours, mas também de incluir as notas originais de aula e os apontamentos de próprio punho, descobrimos um Saussure que não tem nada em comum com o quadro que acaba de ser delineado e é diametralmente oposto ao Saussure estruturalista, pois o que o distingue deste último é precisamente o lugar que a historicidade nele ocupa ${ }^{9}$. Especialmente Henri Meschonnic, a quem as seguintes observações aludem, apontou isso repetidamente. ${ }^{10}$ Eu gostaria de primeiro mostrar até que ponto a concepção saussuriana da arbitrariedade, do sistema e do valor abre a possibilidade de uma

inventário de palavras, à qual toda a teoria linguística de Saussure é dirigida, é convertida em seu oposto exato.

7 "Para Saussure, a língua era um sistema de signos que tem sua própria ordem e que pode ser analisado inicialmente sem recorrer a fatores extralinguísticos como sociedade, história e afins" (NICKEL, 1979, p. 58). "A linguística saussuriana admite uma consideração do sistema linguístico, da langue, como diz também Saussure, somente sob aspecto sincrônico; em outras palavras, ela permite bem a análise de estados do sistema linguístico, mas não a investigação de sequências de estados e, portanto, nenhuma solução para o problema da dinâmica linguística" (HABEL/KANNGIEßER, 1978, p. 9). Nesse sentido, Heidrun Pelz enfatiza também a "clara primazia da orientação sincrônica em Saussure" e fala da "nítida rejeição da linguística histórica do século XIX, que procedia de forma puramente diacrônica (=sprachgeschichtlich)" (PELZ, 1987, p. 62). E Imhasly/Marfurt e Portmann afirmam que Saussure abriu "um novo campo de pesquisa para a linguística: o de uma consideração não-histórica 'estruturalista' da língua" (IMHASLY; MARFURT; PORTMANN, 1986, p. 46).

${ }^{8} \mathrm{Na}$ tradução de Herman Lommel, diz: "die Sprache an und für sich selbst betrachtet ist der einzige wirkliche Gegenstand der Sprachwissenschaft" [a Linguística tem por único e verdadeiro objeto a língua considerada em si mesma e por si mesma] (SAUSSURE, 1931, p. 279; 2012, p. 305). Sobre a importância dessa sentença apócrifa para a recepção da Saussure, ver também Tullio De Mauro (SAUSSURE/DE MAURO, 1972, p. 476), Françoise Gadet (1987, p. 22ff.) e Christian Stetter (1992, p. 510).

9 "Le structuralisme est l'un des rôles que joue Saussure dans la théorie du langage. Saussure ne s'y ramène pas. Non seulement parce que l'on revient à sa théorie comme à une théorie en cours, ce qui pourrait n'être qu'un recul, mais parce qu'il ne se réduit pas à un effet qui a eu son histoire" (MESCHONNIC, 1975, p. 208). Meschonnic escreve, no mesmo trecho, sobre o significado da historicidade em Saussure: "Le paradoxe est qu'il contribue à une historicisation du langage, alors qu'il s'était apparemment détourné de l'histoire, en se détournant de l'historicisme, pour penser la langue comme système" (1975, p. 208).

${ }^{10}$ Ver Henri Meschonnic, 1975, p. 208-221. 
historicização radical da língua, que, como ilustrarei com dois exemplos, ainda é tão relevante na época da linguística cognitiva como foi nos tempos dos neogramáticos positivistas.

O ponto de partida de Saussure é a crítica à velha concepção da filosofia da linguagem, segundo a qual a língua deve ser entendida como uma nomenclatura, ou seja, como uma "lista de termos que correspondem a outras tantas coisas" (SAUSSURE, 2012, p. 105) ${ }^{11}$. Se consultarmos apenas o Cours, essa rejeição da concepção da nomenclatura aparece um pouco sem convicção, já que se lê algumas linhas mais adiante:

O signo linguístico une não uma coisa e uma palavra, mas um conceito e uma imagem acústica (SAUSSURE, 2012, p. 106)12.

Aqui, apenas a noção de uma associação entre palavra e coisa parece ser rejeitada, mas não a ideia de listas em si, e essa impressão é ainda mais reforçada quando os editores explicam em uma nota que para "F. de Saussure, porém, a língua é essencialmente um depósito, uma coisa recebida de fora" (SAUSSURE, 2012, p. $106)^{13}$. Que Saussure não apenas desloca a concepção de nomenclatura, mas de fato se afasta dela completamente, só se torna claro quando se consulta suas próprias notas. Lá diz algo como (cito de acordo com a tradução de Johannes Fehr):

$<$ A maioria das concepções que os $>$ filósofos $<$ fazem, ou pelo menos que eles oferecem>, fazem pensar em nosso primeiro pai Adão chamando os <diversos> animais até si e dando a cada um seu nome (SAUSSURE/FEHR, 1997, p. 337) ${ }^{14}$.

Saussure se distancia desse modelo, considerando em primeiro lugar:

que o fundamento da linguagem [ $>$ langage $<$ ] $<$ não $>$ é formado por nomes. É uma coincidência se o signo corresponde a um objeto

\footnotetext{
${ }^{11}$ N. do T.: para as citações do Curso de Linguística Geral, utilizei a tradução de A. Chelini, J. P. Paes e I. Blikstein para a língua portuguesa, em sua $28^{a}$ edição, publicada pela Editora Cultrix em 2012. "Pour certaines personnes la langue, ramenée à son principe essentiel, est une nomenclature, c'est-àdire une liste de termes correspondant à autant de choses" (SAUSSURE, 1972, p. 97).

12 "Le signe linguistique unit non une chose et un nom, mais un concept et une image acoustique" (SAUSSURE, 1972, p. 98).

13 "[...] pour F. d. Saussure la langue est essentiellement un dépôt, une chose reçue du dehors" (SAUSSURE, 1972, p. 98).

14 " $<$ La plupart des conceptions que se font, ou du moins qu'offrent les> philosophes du langage font songer à <notre premier père> Adam appelant près de lui les < divers> animaux et leur donnant à chacun leur nom" (SAUSSURE/ENGLER, 1967 (I), p. 147, N 12, Nr. 1086).
} 
definido para os sentidos como um cavalo, $\underline{\text { o fogo, }}$, $\underline{\text { c sol }}$ [...] (SAUSSURE/FEHR, 1997, p. 337f) ${ }^{15}$.

Mais importante para ele, porém, é outro argumento: no funcionamento da língua, interfere um "fator imprevisto, que é absolutamente ignorado na combinação filosófica, O TEMPO [...]" (SAUSSURE/FEHR, 1997, p. 339). O fator tempo é de capital importância, pois faz com que toda mudança de signos também implique uma mudança de conceitos, de modo que ambos os níveis, o dos signos e o dos conceitos, não possam ser separados um do outro de forma alguma. Por essa razão, Saussure enfatiza:

a completa insignificância de um ponto de vista [...] que parte da relação do conceito com um signo fora do tempo, fora da transmissão [>transmission $<$, que nos ensina apenas, e experimentalmente, o que vale o signo (SAUSSURE/FEHR, 1997, p. 339f.) ${ }^{16}$.

Para Saussure, o fator tempo e a transmissão, ou seja, o funcionamento da linguagem, estão relacionados tão estreitamente, que ele precisa rejeitar qualquer modelo de linguagem que procure explicar o funcionamento sem levar em conta o tempo. E, de fato, em sua própria teoria da língua, ele colocará tempo e funcionamento em uma relação indissolúvel.

Em Saussure, o passo decisivo para uma nova concepção da língua é dado através do princípio da arbitrariedade. Quase nenhum outro termo em Saussure se tornou tão geralmente aceito e reteve tão pouco do significado que tinha em seu trabalho. Arbitrário significa convencional, de acordo com a imagem clássica de Saussure. ${ }^{17}$ É por isso que não faltou a surpresa de que se visse na terminologia de Saussure uma inovação, afinal, Aristóteles já havia percebido que as palavras não

\footnotetext{
15 '[...] que le fond du langage <n'est> pas constitué par des noms. C'est un accident quand le signe linguistique se trouve correspondre à un objet défini pour les sens comme un cheval, le feu, le soleil [...]" (SAUSSURE/ENGLER, 1967 (I), p. 148, N 12, Nr. 1089).

16 " [...] mais constatons tout de suite l'entière insignifiance d'un point de vue qui part de la relation d'une idée et d'un signe hors du temps, hors de la transmission, qui seule nous enseigne, expérimentalement, ce que vaut le signe" (SAUSSURE/ENGLER, 1967 (I), p. 273, N 12, Nr. 1956).

${ }^{17}$ No dicionário linguístico de Carl Hempel (1976), encontra-se no verbete arbiträr: "Em F. de Saussure, termo para a fixação convencional de um signo; melhor seria a designação 'imotivado', ou seja, a fixação não é 'arbitrária' no sentido da palavra, mas sim a motivação do lexema de base não é mais discernível". E o Metzler Lexikon Sprache expõe no verbete Arbitrarität entre outras coisas: "A atribuição de sentido não ocorre, porém, de modo arbitrário ou imotivado de ser de livre escolha para cada falante individual, mas sim é regulada por convenção dentro de uma comunidade linguística". Semelhantemente: Pelz (1987, p. 48), Imhasly/Marfurt/Portmann (1986, p. 72), Bartschat (1996, p. 68) e Dürscheid (1994, p. 24).
} 
significam algo por natureza, mas por acordo. ${ }^{18}$ É verdade, pois, que o princípio de arbitrariedade de Saussure é dirigido contra qualquer tentativa naturalista de explicar a língua (ou seja, contra qualquer tentativa de derivar a língua de formações onomatopaicas ou da língua gestual), mas também é dirigido contra o naturalismo oculto que influencia a posição convencionalista. Cinco aspectos são característicos do convencionalismo:

1) A concepção de duas ordens, uma natural (a ordem das coisas, ideias e concepções pré-linguísticas) e uma linguística (a ordem das palavras), que estão posteriormente ligadas.

2) $O$ fato de que o princípio de acordo, no qual se baseia o convencionalismo, pressupõe já o entendimento linguístico: não há contrato sem língua. ${ }^{19}$

3) Com isso, também a questão da constituição do significado é sempre considerada como já resolvida. As palavras apenas designam significados que já existiam antes. ${ }^{20}$ 4) O convencionalismo implica uma adesão à concepção de nomenclatura, uma vez que o significado das palavras (e, portanto, sua existência) depende unicamente da relação acordada com as coisas e as ideias.

5) O convencionalismo explica o funcionamento linguístico a partir de um estado anterior ou externo a qualquer historicidade. Exclui, assim, o fator tempo da explicação da natureza semântica da língua.

O quão decididamente Saussure se afastou dessa posição não é imediatamente visível a partir da passagem correspondente do Cours, tanto menos porque os editores não adotaram a formulação original da Saussure. Nas notas preparatórias para o curso, lê-se que a ligação entre significante e significado é radicalmente arbitrária ("le lien unissant le signifiant et le signifié est radicalement arbitraire" SAUSSURE/DE MAURO, 1972, p. 442), enquanto na versão impressa do Cours a declaração foi atenuada pela eliminação de radicalement. O que Saussure entendeu

\footnotetext{
${ }^{18}$ Eugenio Coseriu, por essa razão, vê no "arbitraire du signe somente a forma moderna da teoria aristotélica" (COSERIU, 1992, p. 19). Sobre essa questão, ver também de Mauro/Saussure (1972, p. 381f.).

${ }^{19}$ Fehr escreve sobre esse paradoxo: "Aquele que raciocina desta forma - 'à maneira dos filósofos do século 18' - ignora ou não reconhece, no entanto, que o estabelecimento de um contrato sempre pressupõe uma língua na qual o acordo contratual possa ser concordado" (SAUSSURE/FEHR, 1997, p. 149).

${ }^{20}$ Ver também Jäger (1975, p. 271).
} 
por radicalmente arbitrário, por outro lado, torna-se ainda mais claro nas formulações das notas preparatórias originais para o curso:

A concepção de uma ação na qual, em um determinado momento, os nomes teriam sido atribuídos às coisas, na qual teria sido celebrado um contrato entre as ideias e os signos [...] essa ação existe apenas no reino da ideia ${ }^{21}$.

Ele compara o problema da origem da língua com a questão da origem do Rhône, uma questão que ele descreve como infantil ("puérile"), e prossegue:

O momento da emergência é em si intangível: não se vê. O contrato original coincide com o que acontece todos os dias na língua, com as condições permanentes da língua $[\ldots]^{22}$.

A arbitrariedade exclui assim da teoria linguística qualquer acesso especulativo a um estado anterior à língua e fora da historicidade. Radicalmente arbitrário significa, portanto, radicalmente histórico. Com isso, arbitrário torna-se um verdadeiro contraconceito de convencional. Este é o pré-requisito decisivo para a mudança fundamental de perspectiva em Saussure, que já não procura compreender e descrever a língua a partir de uma cena primeva mítica, mas sim de seu modo de funcionamento histórico. ${ }^{23}$

Com Saussure, não há dimensão da língua que escape à historicidade radical. O princípio da arbitrariedade aplica-se antes de mais nada ao signo, onde tem duas consequências. A primeira é a explicação do modo de funcionamento da língua sem recurso a ideias, concepções e significados pré-existentes. No Cours, diz-se que:

Não existem ideias preestabelecidas, e nada é distinto antes do aparecimento da língua (SAUSSURE, 2012, p. 158) ${ }^{24}$.

\footnotetext{
21 "L'acte idéal par lequel, à un instant donné, les noms seraient distribués aux choses, par lequel un contrat serait passé entre les idées et les signes [...] cet acte reste dans le seul domaine de l'idée" (SAUSSURE/ENGLER, 1967 (I), p.160, D 213, Nr. 1188).

22 "Le moment de la genèse n'est lui-même pas saisissable: on ne le voit pas. Le contrat primitif se confond avec ce qui <se> passe tous les jours dans la langue, <avec les conditions permanentes de la langue:> [...]" (SAUSSURE/ENGLER, 1967 (I), p. 160, II R 20, Nr. 1191).

23 Tullio De Mauro escreve nesse sentido: "Saussure en approfondissant l'analyse des aspects universels de la réalité linguistique, [...] a cerné le caractère radicalement arbitraire et par là radicalement social de toutes les langues: il a ainsi ratifié leur caractère radicalement historique" (SAUSSURE/DE MAURO, 1972, p. XIV). Ver também Henri Meschonnic (1982, p. 29).

24 "II n'y a pas d'idées préétablies, et rien n'est distinct avant l'apparition de la langue" (SAUSSURE, 1972, p. 155).
} 
Com isso, torna-se ainda mais clara a diferença entre arbitrariedade e convencionalidade. No convencionalismo, só pode haver arbitrariedade do lado sonoro do signo, ou seja, do significante, enquanto que em Saussure ambos os lados do signo são arbitrários, o sonoro e o conceptual, significante e significado, e, portanto, o signo como um todo. ${ }^{25}$ Nenhum lado precede o outro. Assim escreve Saussure:

<nunca> tem-se o direito de considerar um lado da linguagem [>langage < ] como < precedente> e superior aos outros, de modo que deva servir como ponto de partida (SAUSSURE/FEHR, 1997, p. $297)^{26}$.

Como segunda consequência da arbitrariedade do signo, resulta, portanto, a inseparabilidade do som e do significado. Saussure ilustrou essa inseparabilidade através da comparação insatisfatória com os dois lados de uma folha de papel; insatisfatória porque se pode realmente olhar apenas para um lado da folha de cada vez. Nas suas notas, Saussure desenvolveu o conceito de sème para sublinhar essa inseparabilidade:

Entre outras coisas, a palavra sème elimina ou deseja eliminar qualquer predominância e qualquer separação inicial entre o lado vocal e o lado ideológico do signo. Ela representa o todo do signo, ou seja, signo e significação unidos em uma espécie de personalidade (SAUSSURE/FEHR, 1997, p. 359) ${ }^{27}$.

O princípio da arbitrariedade está correlacionado com a determinação pelo sistema. Os signos só funcionam através das relações estabelecidas entre si. Fora dessas relações, eles não têm identidade. Qual é a realidade de uma combinação fonêmica como /ze/ em alemão? Ela aparece não só como um substantivo independente ou como membro de composição (die See, die Nordsee, das Seestück), mas também aparece como parte integrante de outras palavras (die Seele, ich sehe, das Ansehen, etc.). Cada elemento da língua só pode ser definido pela sua posição no sistema, sendo que sistema não significa estrutura. Mesmo que a estrutura e o

\footnotetext{
25 "C'est donc par le signe que s'instituent à la fois les signifiés et les signifiants. Aucun des deux plans prééxistent au signe" (GADET, 1987, p. 41).

26 "On n'a <jamais> le droit de considérer un côté du langage comme <antérieur et> supérieur aux autres, et devant servir de point de départ" (SAUSSURE/ENGLER, 1967 (I), p. 26, N 9.1, Nr. 132).

27 "Entre autres, le mot sème écarte, ou voudrait écarter toute prépondérance et toute séparation initiale entre le côté vocal et le côté idéologique du signe. II représente le tout du signe, c'est-àdire signe et signification unis en une sorte de personnalité" (SAUSSURE/ENGLER, 1967 (II), p. 36, N 15, Nr. 3310.12.). Ver também Ludwig Jäger (1986, p. 15).
} 
sistema sejam repetidamente $\operatorname{confundidos}^{28}$, Saussure não utiliza "sistema" em nenhum lugar no sentido de "estrutura". O sistema não pode ser separado da respectiva língua; ele é cada vez único (no sentido de Humboldt), ou seja, histórico, enquanto a estrutura pode ser separada da língua individual e da história, como a estrutura da poesia, em Jakobson, ou a estrutura profunda, em Chomsky. ${ }^{29}$

O quanto o conceito de sistema de Saussure se afasta, por um lado, da compreensão estruturalista do sistema e, por outro, da concepção de listas de palavras é demonstrado pelo conceito de valeur, do valor que Saussure desenvolveu e que é uma consequência direta dos princípios de arbitrariedade e de sistematicidade. É característico da imagem dominante de Saussure que precisamente o conceito de valor tem sido menos capaz de se afirmar e que, portanto, já não é considerado em muitas obras de referência linguística recentes ${ }^{30}$. No valor, ou seja, na atual posição dos elementos no sistema, a historicidade radical da linguagem evidencia-se provavelmente de modo mais direto: a mudança do valor no uso do subjuntivo em alemão, o uso agora exclusivamente irônico de palavras-chave dos anos 80, tais como Betroffenheit ou Selbsterfahrung, a conotação quase nostálgica que o termo ideologia adquiriu após a queda do Muro de Berlim (Der Untergang der (deologien), etc. Como os valores dos elementos linguísticos variam de idioma para idioma, de variedade para variedade e de falante para falante, já que eles estão em um fluxo constante, embora imperceptível, também os sistemas que formam os valores e que são formados por eles estão sempre em movimento ${ }^{31}$.

Se partimos do valor, do sistema e do princípio da arbitrariedade, a historicidade da língua está indissociavelmente ligada ao seu funcionamento. E é nessa integração da historicidade com o funcionamento da língua que está a atualidade da teoria saussuriana da língua. Sua atualidade torna-se imediatamente clara quando se vê qual importância a historicidade da língua recebe em teorias que não partem da

\footnotetext{
${ }^{28}$ Por exemplo, em Lyons (1971, p. 53), Habel/Kanngießer (1978, p. 8), Pelz (1987, p. 43), Gross (1988, p. 22), Linke/Nussbaumer/Pormann (1991, p. 36).

${ }^{29}$ Henri Meschonnic escreve sobre o conceito de sistema de Saussure: "[...] il faut ajouter que système, qui est le terme de Saussure, est historique, en ce qu'il ne sépare pas philologie et linguistique, ce que montre le Mémoire de 1878. Alors que structure est ahistorique, et ne peut que déshistoriciser. En quoi rien n'est plus opposé à Saussure que sa postérité structuraliste" (MESCHONNIC, 1982, p. 29).

30 Não há entrada para valeur ou Wert (valor) em Welte (1974), Hempel (1978), Bußmann (1990) e no Metzler Lexikon Sprache (1993). Em Abraham (1988), valor é equiparado ao conceito de classe, que não pode ser conciliado com o conceito de valor de Saussure.

31 "Le système d'où dépendent ces valeurs est tout le temps momentané" (SAUSSURE/ENGLER, 1967 (I), p.196, D 244, Nr.1469). "Une langue est radicalement impuissante à se défendre contre les facteurs qui déplacent d'instant en instant le rapport du signifié et du signifiant" (SAUSSURE, 1972, p. 112).
} 
arbitrariedade, do sistema e do valor, mas sim continuam uma ou outra variante do convencionalismo. Gostaria de ilustrar isso aqui com apenas dois exemplos, com base em um contemporâneo de Saussure, o neogramático Hermann Paul, e em um representante da teoria linguística mais recente, a saber, o linguista cognitivo Stephen Pinker.

A primeira edição de Prinzipien der Sprachgeschichte (Princípios Fundamentais da História da Língua), de Hermann Paul, foi publicada em 1880; entrementes, a $8^{a}$ edição de sua obra está à venda, o que indica que Paul ainda desempenha um papel na atual discussão sobre mudança linguística ${ }^{32}$. Paul descreve as mais variadas formas de mudança linguística: diversificação e mistura de línguas, mudança fonética, mudança semântica lexical e sintática, fenômenos de formação de palavras e a influência da escrita no desenvolvimento da língua. A abundância de exemplos faz desse livro ainda hoje uma mina de observações individuais interessantes. O que é peculiar na teoria de Paul, porém, é que, para ele, o funcionamento da língua está em contradição direta com a historicidade da língua, que é o verdadeiro objeto do seu livro. Paul parte de uma "combinação primordial de som e significado", que ele descreve como "criação primordial" (PAUL, 1968, p. 35) ${ }^{33}$. Som e Significado são assim entendidos como duas grandezas independentes, apenas ligadas por convenção. Esta separação continua a ser desenvolvida no modelo de comunicação de Paul, porque apenas os sons são transmitidos quando se fala:

Para evocar em uma outra alma a correspondente associação de ideias originadas em si mesma, a alma nada mais pode fazer do que gerar, por meio dos nervos motores, um produto físico, o qual por sua vez, por meio da excitação dos nervos sensíveis do outro indivíduo, evoca as ideias correspondentes na alma deste último, e o faz de uma maneira correspondentemente associada (PAUL, 1968, p. 14) ${ }^{34}$.

A tripla repetição da palavra "correspondente" nessa breve passagem não é capaz de esconder o fato de que, para Paul, é precisamente a correspondência entre som e conceito que apresenta o verdadeiro problema. Paul estava ciente disso, aliás,

\footnotetext{
32 Por exemplo, em Rudi Keller (1994).

${ }^{33}$ N. do T.: as citações de Hermann Paul foram traduzidas por mim. Para cotejo, foi utilizada a edição portuguesa de 1966 da Editora Calouste Gulbenkian, de tradução de Maria Luisa Schemann. Mantive "alma" para Seele, o termo utilizado por Paul no original. No entanto, em sua recepção, o termo também é traduzido por "mente": "In order to evoke in one mind a train of ideas corresponding to one which has taken its rise in another mind" (PAUL, 1891, p. 38).

${ }^{34} \mathrm{~N}$. do T.: na edição portuguesa, há um problema considerável: onde lê-se no original alemão "ein physisches Produkt", encontra-se na citada tradução "um produto psíquico" (PAUL, 1996, p. 23).
} 
porque ele próprio enfatiza que só podemos transmitir sons, mas não o conteúdo da nossa imaginação (PAUL, 1968, p. 15). Segundo Paul, o fato de a troca linguística não ruir a cada segunda enunciação deve-se ao fato de - por quaisquer razões podermos assumir que existe uma certa concordância entre os conteúdos imaginários de cada indivíduo:

Quanto maior for a concordância, mais fácil será o entendimento. Por outro lado, qualquer diferença nessa relação implica não apenas a possibilidade, mas a necessidade da incompreensão, da compreensão imperfeita ou do mal-entendido (PAUL, 1968, p. 15).

O problema então é que o que torna o entendimento possível, nomeadamente a concordância, deveria realmente impedir qualquer transformação na língua, uma vez que toda transformação colocaria em perigo ou destruiria a concordância. De pouco serve, também, quando Paul explica a mudança dos significados das palavras pelo fato de um falante associar um novo conteúdo imaginário a uma palavra, "à qual ele espera que também o ouvinte associe" (PAUL, 1968, p. 75). O que justifica essa expectativa? Como ele pode sequer saber que se trata de um novo conteúdo da imaginação, uma vez que só se pode conhecer o próprio? O modelo de mudança linguística de Paul faz lembrar do homem do conto Ein Tisch ist ein Tisch [Uma mesa é uma mesa], de Peter Bichsel, que de início por aborrecimento troca os nomes dos objetos e ao fim já não é mais compreendido por ninguém. O que falta a Paul é uma concepção do valor que explique que palavras como Weib, Pfaffe, Mähre, Bube [mulher, fradalhão, pangaré, menino] mudaram o seu significado porque surgiram novas oposições e, como resultado, a posição das palavras no sistema linguístico se modificou gradualmente. A aderência ao convencionalismo separa funcionalidade e historicidade através de uma lacuna intransponível.

Isso se aplica do mesmo modo ao segundo exemplo, o livro recentemente publicado por Stephen Pinker, também em alemão, com o título provocador: The Language Instinct (1994) ${ }^{35}$. Pinker tenta provar a existência de uma gramática universal inata através de uma multiplicidade de argumentos, anedotas e resultados de investigação. Na série de linguistas famosos que ele passa em revista, também não falta o nome Saussure. Ele representa a arbitrariedade do signo, que Pinker, no

\footnotetext{
${ }^{35} \mathrm{~N}$. do T.: para as citações da obra de Pinker, utilizei a tradução de Claudia Berliner para a língua portuguesa, publicada pela Editora Martins Fontes em 2004.
} 
entanto, compreende como uma "a combinação totalmente convencional de um som com um significado"36. A convencionalidade é um dos dois princípios (Pinker fala de truque, no sentido de truque da natureza) em que se baseia o funcionamento da língua. O outro princípio é a existência de um conjunto de regras, de uma gramática gerativa, através da qual os signos convencionais estão ligados para formar unidades maiores, nomeadamente frases (PINKER, 1994, p. 84). Esse modelo de língua não deixa espaço para a historicidade, porque a língua só pode funcionar se as convenções uma vez estabelecidas e as regras gramaticais, que são aliás inatas, forem respeitadas. De acordo com a concepção de língua de Pinker, portanto, não deve haver historicidade na língua ou, no máximo, como uma violação da natureza da língua. O que é espantoso no livro de Pinker é que ele aborda, contudo, as diferentes formas de mudança linguística sem qualquer timidez e faz frequentes digressões na história da língua. Só numa inspeção mais atenta é que se torna claro porque Pinker pode, por um lado, dedicar-se ao lado histórico da língua e, por outro, afirmar que a língua é uma disposição inata. De fato, Pinker usa a palavra "language" em dois significados diferentes, mutuamente excludentes do ponto de vista lógico. Por um lado, ele refere-se com "language" às postuladas estruturas inatas da língua:

A linguagem não é um artefato cultural que aprendemos da maneira como aprendemos a dizer a hora ou como o governo federal está funcionando. Ao contrário, é claramente uma peça da constituição biológica de nosso cérebro (PINKER, 2004, p. 9) ${ }^{37}$.

Essa "language" é imutável. A "language" só pode mudar no sentido de "língua concreta”. Duzentas páginas mais tarde, Pinker escreve:

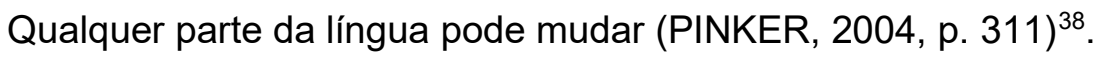

E:

[...] sempre, em todas as comunidades, a língua muda, embora as várias partes de uma língua possam mudar de maneiras diferentes em diferentes comunidades (PINKER, 2004, p. 315).

\footnotetext{
36 "The first principle, articulated by the Swiss linguist Ferdinand de Saussure, is »the arbitrariness of the sign, « the wholly conventional pairing of a sound with a meaning" (PINKER, 1994, p. 83).

37 "Language is not a cultural artifact that we learn the way we learn to tell time or how the federal government works. Instead, it is a distinct piece of the biological makeup of our brains" (PINKER, 1994, p. 83). Sobre a relação entre Saussure e a linguística cognitiva, ver também Jäger (1990).

38 "Any part of language can change" (PINKER, 1994, p. 83).
} 
Cada parte da língua pode mudar significa: cada parte, exceto o nível semântico. Afinal, a semântica, o pensamento e os significados só estão ligados por convenção à língua e são, de resto, independentes dela. Pinker fala expressamente de uma "linguagem do pensamento", de uma "language of thought" em que todos os processos cognitivos ocorrem independentemente da língua ${ }^{39}$. Com Pinker, poderíamos falar de uma historicidade sem sentido; sem sentido, uma vez que o sentido, a semântica e o pensamento permanecem fora da historicidade, mas também de uma historicidade sem sentido, porque todas as mudanças reais na língua, por mais incisivas que sejam, adquirem assim o estatuto de meras modificações formais. A historicidade torna-se uma mera formalidade. Tal como "language" enquanto fenômeno cognitivo e "language" enquanto fenômeno de língua não se podem unir, assim também no trabalho de Pinker a historicidade e o funcionamento da língua não podem ser conciliados. $O$ fato de uma e a mesma palavra ser usada aqui para dois conceitos diferentes só pode esconder a diferença entre os dois, mas não a eliminar.

A atualidade de Saussure não reside no fato de ele conseguir transpor essa diferença, mas no fato de ela nem sequer surgir quando - como no seu caso - o próprio funcionamento da língua é radicalmente histórico. Se, de um lado, isso foi obscurecido pela imagem clássica de Saussure e por algumas intervenções dos editores do Cours, por outro, torna-se ainda mais evidente nas suas notas, por exemplo, quando escreve:

Não há exemplo de imobilidade absoluta [>imobilité absolue<]. O que é absoluto é o princípio do movimento da língua [>langue $<$ ] no tempo (SAUSSURE/FEHR, 1997, p. 392) ${ }^{40}$.

E em outra passagem:

[...] deve-se de fato, de uma vez por todas, colocar-se fora e acima da velha concepção segundo a qual a imobilidade e a unidade seriam o destino normal de cada língua [>langue $<$, mais normal pelo menos

\footnotetext{
39 "People do not think in English or Chinese or Apache; they think in a language of thought" (PINKER, 1994, p. 81). Pinker também se refere à linguagem do pensamento como "mentalese", "mentalês", que ele define da seguinte forma: "The hypothetical »language of thought«, or representation of concepts and propositions in the brain in which ideas, including the meanings of words and sentences, are couched" (PINKER, 1994, p. 478). O mentalês é, assim, ao mesmo tempo, independente da língua e a sua contraparte exata. $O$ convencionalismo sempre pressupõe a língua.

40 "Il n'y a pas d'exemple d'immobilité absolue. Ce qui est absolu, c'est le principe du mouvement de la langue dans le temps" (SAUSSURE/ENGLER, 1967 (I), p. 318, N 23.1, Nr. 2205).
} 
que a mudança, o movimento e a diversidade (SAUSSURE/FEHR, 1997$, p. 415$)^{41}$.

Como Saussure começa a pensar a língua a partir de sua historicidade radical, ele permanece presente na teoria atual da linguagem, mas não como uma autoridade, porque ainda quebra padrões familiares de pensamento e, portanto, cria mais contradição do que consenso. Mas, se o consenso também é o material a partir do qual a autoridade é forjada, a contradição é o ar que a ciência precisa respirar. E da obra de Saussure sopra uma brisa fresca em direção ao futuro.

\section{Referências}

ABRAHAM, Werner. Terminologie zur neueren Linguistik. Tübingen: Niemeyer, 1988.

ARNOLD, Heinz Ludwig; SINEMUS, Volker. Grundzüge der Literatur- und Sprachwissenschaft, Bd. 2: Sprachwissenschaft. Nördlingen: Deutscher Taschenbuch-Verlag, 1974.

BARTSCHAT, Brigitte. Methoden der Sprachwissenschaft, von Hermann Paul bis Noam Chomsky. Berlin: Erich Schmidt, 1996.

BUßMANN, Hadumod. Lexikon der Sprachwissenschaft, 2. Aufl. Stuttgart: Kröner Verlag, 1990.

COSERIU, Eugenio. Einführung in die Allgemeine Sprachwissenschaft. Tübingen: Francke, 1992.

DÜRSCHEID, Christa; KIRCHER, Hartmut; SOWINSKI, Bernhard. Germanistik, Eine Einführung. Köln: Böhlau, 1994.

GADET, Françoise. Saussure - une science de la langue. Paris: PUF, 1987.

GROSS, Harro. Einführung in die Germanistische Linguistik. München: ludicium, 1988.

HABEL, Christopher; KANNGIEßER, Siegfried. Prolegomena zu einer NichtSaussureschen Linguistik. In: HABEL, Christopher; KANNGIEßER, Siegfried. Sprachdynamik und Sprachstruktur, Ansätze zur Sprachtheorie. Tübingen: Niemeyer, 1978.

HEMPEL, Carl. Linguistisches Wörterbuch. München: Deutscher Taschenbuch Verlag, 1978.

\footnotetext{
41 "C'est qu'en effet il faut se placer une fois $p(o u) r t(o u) t(e) s$ en dehors et au dessus de la vieille conception selon laquelle l'immobilité et l'unité semblait [[la]] la destinée normale de chaque I(an)gue [[]], du moins [[] plus normale que le changement, le mouvement et la diversité", publicado pela primeira vez em um ensaio de A. Prosdocimi (1983, p. 95).
} 
IMHASLY, Bernard; MARFURT, Bernhard; PORTMANN, Paul. Konzepte der Linguistik, Eine Einführung. 1. Auflage 1979. Wiesbaden: Aula-Verlag, 1986.

JÄGER, Ludwig. Zu einer historischen Rekonstruktion der authentischen Sprach-Idee Ferdinand de Saussures. Bübingen: 1975.

JÄGER, Ludwig. Der Saussuresche Begriff des Aposème als Grundlagenbegriff einer hermeneutischen Semiologie. In: JÄGER, Ludwig; STETTER, Christian. Zeichen und Verstehen, Saussure Kolloquium 1983. Aachen: Rader Verlag, 1986.

JÄGER, Ludwig. Die semiologische Kritik des linguistischen Segmentalismus, Die Sprachidee F. d. Saussures und die kognitivistische Herausforderung der Linguistik. In: Présence de Saussure, actes du colloque international de Genève (21-23 Mars 1988). Publicado por René Amacker e Rudolf Engler. Genf: Librairie Droz, 1990.

KELLER, Rudi. Sprachwandel, Von der unsichtbaren Hand in der Sprache. Tübingen: Francke, 1994.

LYONS, John. Einführung in die moderne Linguistik, München: C. H. Beck Verlag, 1971.

MESCHONNIC, Henri. Le signe et le poème. Paris, Editions Gallimard: 1975.

MESCHONNIC, Henri. Critique du rythme. Paris: Verdier, 1982.

Metzler Lexikon Sprache. Publicado por Helmut Glück. Stuttgart: J. B. Metzler, 1993.

NICKEL, Gerhard. Einführung in die Linguistik, Entwicklung, Probleme, Methoden, Berlin: E. Schmidt, 1979.

PAUL, Hermann. Principles of the history of language. Tradução inglesa de Herbert Augustus Strong. London/New York: Longmans, Green edition, 1891.

PAUL, Hermann. Princípios Fundamentais da História da Língua. Tradução de Maria Luisa Schemann. Lisboa: Calouste Gulbenkian, 1966.

PAUL, Hermann. Prinzipien der Sprachgeschichte, 1. Aufl. 1880. Tübingen: Niemeyer, 1968.

PELZ, Heidrun. Linguistik für Anfänger, 1. Aufl. 1975. Hamburg: Hoffmann und Campe, 1987.

PINKER, Steven. The Language Instinct - The New Science of Language and Mind. New York: William Morrow and Company, 1994.

PINKER, Steven. O instinto da linguagem - Como a mente cria a linguagem. São Paulo: Martins Fontes, 2004. 
PROSDOCIMI, Aldo. Saussure delle leggende germaniche. In: Cahiers Ferdinand de Saussure 37. Genf: Librairie Droz, 1983.

RILKE, Rainer Maria (1902). Rodin. In: Werke in sechs Bänden, Band III, 2, Prosa. Frankfurt am Main: Insel Verlag, 1982.

SAUSSURE, Ferdinand de (1931). Grundfragen der allgemeinen Sprachwissenschaft. Tradução alemã de Herman Lommel, 2a edição. Berlin: de Gruyter, 1967.

SAUSSURE, Ferdinand de. Cours de linguistique générale. Edição crítica preparada por Rudolf Engler. Wiesbaden: Harrassowitz, 1967.

SAUSSURE, Ferdinand de. Cours de linguistique générale. Edição crítica preparada por Tullio De Mauro. Paris: Edition Payot, 1972.

SAUSSURE, Ferdinand de. Linguistik und Semiologie, Notizen aus dem Nachlaß, Texte, Briefe und Dokumente. Organizado, traduzido e introduzido por Johannes Fehr. Frankfurt am Main: Suhrkamp, 1997.

SAUSSURE, Ferdinand de. Curso de Linguística Geral. Tradução de Antônio Chelini, José Paulo Paes e Izidoro Blikstein. São Paulo: Cultrix, 2012.

STETTER, Christian. Ferdinand de Saussure (1857-1913). In: Sprachphilosophie, Ein internationales Handbuch zeitgenössischer Forschung. Organizado por Marcelo Dascal, Dietfried Gerhardus, Kuno Lorenz, Georg Meggle, Bd. 1. Berlin: de Gruyter, 1992.

WELTE, Werner. Moderne Linguistik, Terminologie / Bibliographie, ein Handbuch und Nachschlagewerk auf der Basis der generativ-transformationellen Sprachtheorie, 2 Bde. München: Max Hueber Verlag, 1974. 